\title{
Mind your Anxiety: a case of a 30 years old male
}

\author{
Dr, Rachana Awatramani \\ Counseling Psychologist \\ Corresponding author: Rachana Awatramani \\ Email - rachana.awatramani@gmail.com
}

\begin{abstract}
This case highlights the concern of a 30-year-old client, who complained of fear of leaving his house and experiencing anxiety symptoms while travelling. Two events described, seemed to trigger his fear. This had caused a significant deterioration in his social and occupational functioning to an extent that he opted for work from home. Client centered approach, mindfulness breathing and behavior technique including muscle relaxation seemed to help the client to cope with his issues. State Trait Anxiety Inventory (STAI) showed difference in scores pre and post counselling sessions. This suggests that anxiety can have serious effects on one's personal and professional life. However, with timely intervention, one can learn to deal with it effectively.
\end{abstract}

Keywords: Anxiety, Fear, Counselling, Behaviour Technique, Mindfulness, Breathing

(Paper received $-28^{\text {th }}$ September 2020, Peer review completed $-10^{\text {th }}$ November 2020)

(Accepted $-18^{\text {th }}$ November 2020)

\section{INTRODUCTION}

Mental disorders are on rise globally. A study which intended to capture the burden of mental disorders across Indian states concluded that 197.3 million people had mental disorders out of which 45.7 had depressive disorders and 44.9 million with anxiety disorders in 2017. It also highlighted that in 2017, one in seven people in India had mental disorders with symptoms ranging from mild to severe [1].

\section{Anxiety}

Certain life events/situations make certain people anxious. For example, going for an interview or giving a speech or preparing for exams. In such cases, being anxious helps us to boost our performances or helps us to prepare better. But when this anxiousness, starts to take a ramp on our personal, social, occupational or other important domains of life, then it is considered problematic. There is a very fine line between normal anxiety and excessive anxiety. For instance, anxiety is considered to be pathological when it is experienced even in the absence of stimuli or challenge. Additionally, the severity and the intensity is disproportionate to the stimuli/challenge. Lastly, the individual experiences significant distress which impairs psychological, social, occupational and other important domains of life [2]. The common feature of anxiety disorders is that of excessive fear and anxiety and behavioural disturbances. Since anxiety mainly arises because of the anticipated future threat, the individual experiencing the same engages in cautious or avoidant behaviours, which helps to lessen its intensity [3]. 


\section{Mindfulness and how it befriends anxiety}

Mindfulness is awareness, cultivated by paying attention in a sustained and particular way: on purpose, in the present moment, and non-judgementally. It is one of many forms of meditation, if you think of meditation as any way in which we engage in (1) systematically regulating our attention and energy (2) thereby influencing and possibly transforming the quality of our experience (3) in the service of realizing the full range of our humanity and of (4) our relationships to others and the world [4]. The way we categorize things, situations or people into good, bad, beautiful, ugly, easy, difficult depends upon how our mind perceives it. Mindfulness is a flexible state of mind. In other words, it includes openness to new ideas, experiences which makes one aware of the context and perspective of one's present situation [5]. Although strategies such as distraction, thought suppression or use of harmful substances for regulating emotions may provide a relief on temporary basis, it can not only be reinforcing but can become habitual, automatic, and rigid. Research has shown that practicing mindful breathing daily reduced test anxiety for under graduate students. Additionally, it also highlighted the role of mindfulness based breathing practice in increment of automatic positive thoughts compared to the control group [6].

Another study which investigated the Impact of Jacobson Progressive Muscle Relaxation (JPMR) and Deep Breathing Exercises found reduction in anxiety, psychological distress, and improving quality of sleep among their experimental group [7]. Vollestad and others [8] in a systematic review and meta-analysis concluded that Mindfulness and acceptance-based interventions was associated with reduction in symptoms of anxiety and comorbid depressive symptoms. Thus, mindfulness acts as a mediator that promotes a wise and accepting relationship with one's cognitions, emotional and physical experience even during times of extreme fear and worry. And hence, mindfulness empowers one to choose a wise response wherein anxiety is noticed, allowed and responded to with openness, curiosity and acceptance. This not only increases distress tolerance, but also disrupts habitual avoidance, and promotes adaptive self-regulation and healthy mind/body functioning [9].

\section{Presenting Problem}

The presented case is of a 30 years old male client, who experienced extreme anxiety symptoms when he had to travel alone. His anxiety had been increasing day by day. He had visited multiple doctors including a psychiatrist and was suggested to go for therapy. All his medical reports were normal therefore he decided to meet a counsellor for professional guidance. For the first session, he was accompanied by his sister and later by his driver and sometimes he used to visit the counselling centre with one of his friends. The client had willingly decided to seek help from a professional. He found the contact of the counsellor with help of his sister, who asked for a recommendation from her nutritionist.

He had sought help from the therapist with main concern being fear of leaving the house and wanted to work on the same as it made him frustrated. This especially seemed to hinder his social and occupational life. He was absolutely fine if he had a company with him, like his friends in his own locality however when he had to move outside his locality he would start experiencing anxiety, even though he was accompanied by someone, it was challenging for him to believe that everything is fine. He worked for an IT firm, he had taken work from home, so that he could avoid stepping out of his house. Even though if he had to leave the house for miscellaneous reasons, he ensured that he was always accompanied by someone. Upon probing by the therapist, the client revealed that if he left his house he had thoughts such as "something will happen to me", "What if my health is affected", and "What if there are no doctors" and "What if I die"? Additionally, he would also gather information about hospitals located on the route, which he was going to take on that particular day. He would also check his Blood Pressure every two hour to make sure everything is fine with him. If in case if he noticed any fluctuations in his blood pressure, he would call the doctor immediately.

He mentioned the following symptoms when he went outside the house: uneasiness, worry, fear, palpitation, sometimes trembling, too many thoughts about something will go wrong, which would impact his health and restlessness. 


\section{Relevant Background Information}

The client was well groomed, appeared conscious and was oriented to time, place and person. No unusual details were observed in his Mental Status Examination. The client hails from a middle socio-economic stratum and resided with his mother, father, two paternal aunt and a younger sister. The client also mentioned about his previous habit of smoking cigarettes but he had already quit by the time he came for his initial counselling session. He was smoking from past two years and had quit six months ago before he started counselling. The counsellor advised him to get his blood test done and it was found that his Vitamin B and D3 levels were low. Apart from that he had already found that all his medical reports were normal and he was recommended to see a psychologist to overcome his fear and anxiety. He also witnessed two stressful events that seemed to be the trigger his fear. The first event, which was around five years ago, when he served as a helping hand in his holy place of worship, where he witnessed a few deaths and actively participated in the final rituals of the death ceremony. Second event was around two years ago, during rainy days, when he was stuck and had to walk in order to reach home. Although he reached home safely and reported no concerns during that particular time, but his fear begins to build up gradually thereafter.

\section{Intervention}

Initial aim of first two sessions was to build rapport and allow the client to be comfortable and trust the process. Therefore, client centered approach let the client lead and express, with providing unconditional acceptance and a safe space for him to speak his fears. By the end of first session, he was also asked to fill State Trait Anxiety Inventory (STAI) questionnaire. Along the session, case history was also obtained. He spoke about two instances that could have been the reason for his anxiety, the volunteering service and the incident during the rainy season. This session was also dedicated to understand his expectations and goals from the counselling sessions. He mentioned he wants to travel fearlessly and also feel confident to move out of the house alone.

In the second session, he also shared about his daily routine and with help of the therapist he wanted to modify his routine and add physical exercise in that, he willingly chooses to go to the gym as it was closer to his house and also his friend were active members there. The technique of focusing on breathing was introduced to him and he was suggested to practice breathing exercise after his gym every day. He scored 53 in State anxiety and 40 in Trait anxiety, which indicated severe anxiety on the inventory scale. On probing further to understand his state anxiety scores he mentioned that he was anxious to come for a counselling session and was extremely worried on how things will turn out. He did not want to be judged, nevertheless the confidentiality policy made him comfortable to share more openly.

By the third session, he was introduced to the behavior technique of muscle relaxation along with practicing breathing exercise of mindfulness every two hour every day. He had started to feel the difference and felt comfortable practicing to focus on the breathing. Followed, he also used it whenever he felt anxious. This pattern was usually followed for a month by the client, which proved to be helpful and efficient for him.

By the fourth session, he was comfortable going to the gym by himself and also to buy few things for his house. It was comfortable for him to move alone in the local area. This time the therapist used behaviour therapy with the aim of reversing the behavior pertaining to the avoidance of going outdoors. He was ready to travel with his driver to a little long distance and also agreed to one day visit to his work place which was about 100 kilometers away from his home. He was probed to share what does he usually do in the car and what gives him the feeling of safety. He mentioned, "If he has someone with him, he is comfortable however, he needs to know all the hospitals around and travelling on the highway scares him as he cannot see any buildings and hospitals accessible". He was asked to make the list of things that he can do while he is in the car, he came up with the following: 1. listening to music, 2. talking to the driver, 3. drinking water and 4 . playing game on the phone. He agreed to travel to distance of about 50 kilometers using the above list.

In the fifth session, he shared that breathing exercises was helping him. He mentioned that he travelled once with his driver and once with his friend about 50-60 kilometers and while travelling, talking to the person he was travelling with was helpful. He was comfortable and ready to travel to work once a week, which was about 100 kilometers away from his house. Mind rehearsal technique was used in this session, where he was asked to imagine the day, he wakes up and gets ready to go to work and was guided through the entire way to reach office in his imagination. He was comfortable throughout the exercise. The four things that he 
mentioned earlier were used during the instructions which helped him reach work comfortably and also reach back home safely without experiencing anxiety symptoms. He was instructed stating that he was ready with all the emergency contact, he was travelling with the driver, he was speaking to the driver and trying to know more about the driver. He was sipping water and also had a stress ball with him during the journey. He successfully imaged his travel to work and back home. He felt more confident to travel to work and was looking forward to go to office.

During the sixth session, which was after one month, he mentioned that he travelled to work twice a week and was feeling comfortable. He practiced two-minute breathing exercise 3-4 times in a day and muscle relaxation technique once a week. He went to the gym three times a week. This session focused on summarizing the first five sessions and to address his concerns if any. The client was asked how many times he checked his blood pressure in last one month. He mentioned his habit of checking blood pressure has disappeared and since a month he does not even know where the machine is. He wanted to continue with his practices as he was feeling more confident and willing to increase the number of days he could go out. He wanted to travel alone and also explore dating. During the end of the session he was asked to fill up STAI questions once again and he scored 35 in state and 29 in trait anxiety which indicated severe state anxiety and moderate trait anxiety. Both state and trait anxiety scores had reduced, indicating improvement in the anxiety levels of the client.

\section{Recommendations}

The client was recommended to see the therapist once a month for follow-up sessions. He wanted to focus on traveling alone and he had a long-term goal of travelling inter cities as well as internationally as he used to before. He was guided to break his long-term goals into small goals as he was progressing at achieving them slowly. He was also suggested to continue breathing exercises every day.

\section{Conclusions}

Across six sessions in four months, the client learnt to manage his fear of leaving his house with mindfulness breathing technique. In addition, behavior therapy and daily routine modification also seemed to play a role in curbing his anxiety. The client travelled to his workplace which was 100 kilometers away from his home. Even though he was accompanied by his driver, he was taught strategies to keep himself busy till he reached his destination so as to avoid distressing thoughts. After a month he was able to move alone and had started to go out on dates. However, he was still travelling to work with the driver but he was confident and was coping with the situation with least stress. It was also client's dedication to help himself that added to the successful outcome of the therapy.

\section{REFERENCES}

1. Sagar R, Dandona R, Gururaj G, Dhaliwal RS, Singh A, Ferrari A, Dua T, Ganguli A, Varghese M, Chakma JK, Kumar GA. The burden of mental disorders across the states of India: the Global Burden of Disease Study 1990-2017. The Lancet Psychiatry 2020;7(2):148-61.

2. Coltrera F. Anxiety: What it is, what to do. Retrieved from https://www.health.harvard.edu/blog/anxiety-what-it-is-what-to-do-2018060113955; 2018.

3. American Psychiatric Association. Diagnostic and Statistical Manual of Mental Disorders, 5th Edition: DSM-5 (5th ed.). Arlington, VA: American Psychiatric Publishing; 2013.

4. Kabat Zinn J. Mindfulness For Beginners. Mumbai, Maharashtra: JAICO Publishing House; 2017.

5. Langer A. Well- Being: Mindfulness Versus Positive Evaluation. In Snyder, C.R \& Lopez, S.J, Handbook of Positive Psychology. Retrieved from http://ldysinger.stjohnsem.edu/@books1/Snyder_Hndbk_Positive_Psych/Snyder_Lopez Handbook of Positive Psychology.pdf; 2002.

6. Cho H, Ryu S, Noh J, Lee J. The Effectiveness of Daily Mindful Breathing Practices on Test Anxiety of Students. Plos One 2016;11(10):e5072593.

7. Khakka NDC, Satapathy S, Dey AB. Impact of Jacobson Progressive Muscle Relaxation (JPMR) and Deep Breathing Exercises on Anxiety, Psychological Distress and Quality of Sleep of Hospitalized Older Adults. J Psychosoc Res 2015;10(2):211-23. 
8. Vollestad J, Nielsen MB, Nielsen GH. Mindfulness- and acceptance-based interventions for anxiety disorders: A systematic review and meta-analysis. Br J Clin Psychol 2016;51(3):239-60.

9. Greeson J, Brantley J. Mindfulness and Anxiety Disorders: Developing a wise relationship with the Inner Experience of Fear. In Didonna, F., Clinical Handbook of Mindfulness. Retrieved from https://books.google.co.in/books?id=1lw4701SDAcC\&printsec=frontcover\&dq=Mindfulness\&hl=en\&s a=X\&ved=0ahUKEwjvleCZ2ZzpAhU9yDgGHTYABUk4ChDoAQhuMAg; 2009.

Acknowledgements - Nil

Conflict of Interest - Nil

Funding - Nil 